\title{
$\infty \sqrt{1}$ Stroke and \\ Treating supratentorial intracerebral haemorrhage: hopeless? Or rethink our strategy
}

David Z Wang, ${ }^{1}$ Liping Liu (D),${ }^{2,3}$ Guohua Xi, ${ }^{4}$ Yongjun Wang (D) ${ }^{2,3}$

To cite: Wang DZ, Liu L, Xi G, et al. Treating supratentorial intracerebral haemorrhage: hopeless? Or rethink our strategy. Stroke \& Vascular Neurology 2021;6: e001043. doi:10.1136/svn-2021-001043

Received 2 April 2021 Accepted 6 April 2021 Published Online First 15 April 2021
Check for updates

(c) Author(s) (or their employer(s)) 2021. Re-use permitted under CC BY-NC. No commercial re-use. See rights and permissions. Published by BMJ.

${ }^{1}$ Neurovascular Division, Department of Neurology, Barrow Neurological Institute, Phoenix, Arizona, USA

${ }^{2}$ Department of Neurology, Beijing Tiantan Hospital, Capital Medical University, Beijing,

China

${ }^{3}$ China National Clinical Research Center for Neurological Diseases, Beijing, China

${ }^{4}$ Department of Neurosurgery, University of Michigan, Ann Arbor, Michigan, USA

Correspondence to Dr David Z Wang;

david.wang@dignityhealth.org
Intracerebral haemorrhage (ICH) is the deadliest $(40 \%)$ among all strokes. ${ }^{1}$ There are about 2 million ICHs annually worldwide, but effective treatment is still lacking. An ICH volume of $<30 \mathrm{~cm}^{3}$ may have a 30-day mortality of $19 \% .^{2}$ Clinical research on treating ICH has been focusing on blood pressure control, haemostatic therapy, surgical evacuation of the clot and effective drainage of intraventricular blood. The principles behind these therapies include stopping the haemorrhage, preventing haematoma expansion, reducing the clot burden, reducing intracranial pressure and preventing obstructive hydrocephalus. However, the outcome of these trials has not been ideal. Only tight blood pressure control and posterior fossa haematoma evacuation have been incorporated into the standard clinical practice.

Recently, Stroke and Vascular Neurology published two articles online on the aspect of using haemostatic therapy for ICH. The Tranexamic acid for acute intracerebral hemorrhage growth based on imaging assessment (TRAIGE) trial studied the effect of tranexamic acid on reducing the risk of haematoma expansion in patients with ICH with either the black hole, blend or spot sign on noncontrast CT or CT angiography. ${ }^{3}$ These three radiological findings in patients with ICH are indicative of higher risk of haematoma expansion. After randomising 171 patients to tranexamic acid or placebo within 8 hours of onset, the intent to treat analysis did not show a benefit of reducing the growth of ICH, but a trend of lowering the risk of mortality $(8.1 \%$ vs $10.0 \%, \mathrm{p}=0.71)$. The meta-analysis of four randomised large trials studying recombinant factor VIIa or tranexamic acid in ICH showed the benefit of reducing haematoma size with haemostatic therapy in those with a black hole sign on CT $(p=0.03)$. However, no improvement of functional outcome or reduction of mortality was seen. ${ }^{4}$
Surgically, in Efficacy and safety of minimally invasive surgery with thrombolysis in intracerebral haemorrhage evacuation (MISTIE III), minimal invasive evaluation of haematoma plus infusion of tissue plasminogen via a catheter showed good function outcome in $58 \%$ of patients who had their haematoma reduced to a volume of $<15 \mathrm{~mL}$. In this subgroup, there was a $10.5 \%$ difference in the likelihood of achieving a good functional outcome favouring surgical treatment $(p=0.03) .^{5}$ Two Surgical Trial in Lobar Intracerebral Haemorrhage I and II) trials randomised 1541 patients with ICH to early surgery or conservative treatment showed a nonsignificant benefit of surgery if patients with ICH had a Glascow Coma Scale (GCS) score of 9-12 and the volumes of ICH were large. ${ }^{6}$ In CLEAR III trial (thrombolytic removal of intraventricular haemorrhage in treatment of severe stroke), the treatment group had a lower case fatality $(46(18 \%)$ vs saline 73 (29\%), HR 0.60 (95\% CI 0.41 to $0 \cdot 86), \mathrm{p}=0.006)$, but a greater proportion with modified Rankin scale (mRS) 5 (42 (17\%) vs $21(9 \%)$; RR 1.99 (95\% CI 1.22 to 3.26$)$, $\mathrm{p}=0.007)$ at 180 days. $^{7}$

It appeared that both haemostatic and surgical therapies showed trend of benefit in either mortality or functional outcome in subgroups of patients with ICH but not in all outcome measures. Pathophysiologically, the damage of the brain from an ICH begins with a space occupying bleeding 'ball', followed by damages to the core of haemorrhage and surrounding brain tissue from blood components (eg, brain iron overload), ${ }^{8}$ brain oedema, oxidative stress and inflammatory responses. The novel iron chelator deferoxamine mesylate was tested in phase 2 trial in patients with ICH within 24 hours of onset. Although no significant difference in efficacy, secondary analysis showed that deferoxamine group had more mRS of 0-2 at 180 days, $45 \%$ versus $36 \%$ (absolute risk reduction of $8.6 \%$ at a $90 \%$ upper confidence bound), and if 
given within 12 hours of onset, a trend of reduced perihematomal oedema was also seen. ${ }^{9}$

Most ICH-related treatment trials have been using the traditional ordinal mRS to evaluate the outcome. However, dichotomised mRS scores may not always detect the treatment benefit when functional outcome is designated as independent (mRS, 0-2) and dependent or dead (mRS, 3-6). Recently utility-weighted mRS may be a better choice since it incorporates the quality of life in outcome analysis and measures both the treatment effect and patient's perception of functional status. ${ }^{10} \mathrm{It}$ captures what survivors consider as important. Furthermore, trials evaluating medical treatment of ICH mostly assess the outcome at 90 days, which may be too short to detect any improvement. As in surgical trials, evaluating the outcome at 180 or 365 days would potentially show trends of treatment benefit. ${ }^{1112}$

Therefore, treating ICH is not hopeless. Benefits seen from the above mentioned subgroup analysis are opportunities for large trials. Meanwhile, in clinical practice, strategies of treating ICH could be planned based on the time of onset, size and location of haematoma or presence of intraventricular expansion, patient's age, GCS score, spot or blend sign or amyloid changes on CT or MRI. If a haematoma is $<15 \mathrm{~cm}^{3}$ in size, one of the haemostatic therapies could be initiated within 2 hours of onset plus aggressive control of blood pressure. If the size of a haematoma is $>15 \mathrm{~cm}^{3}$, haemostatic therapy plus aggressive control of blood pressure plus surgical evacuation plus iron chelation could be considered in $<12$ hours of onset. Thrombolytics can be added to facilitate the removal of blood if intraventricular haemorrhage is present. Approaching ICH with only one type of intervention may be a thing of the past. Now is the time to design trials that will test the combination of medical therapy and surgical interventions together to treat an ICH.

Contributors DW, LL, GX and YW all had contributed in the planning and performing of literature search in preparation of this editorial. DW drafted the manuscript. LL, GX and YW completed the critical revision. All authors reviewed, edited and approved the final version.

Funding The authors have not declared a specific grant for this research from any funding agency in the public, commercial or not-for-profit sectors.

Competing interests None declared.

Patient consent for publication Not required.
Provenance and peer review Commissioned; internally peer reviewed.

Open access This is an open access article distributed in accordance with the Creative Commons Attribution Non Commercial (CC BY-NC 4.0) license, which permits others to distribute, remix, adapt, build upon this work non-commercially, and license their derivative works on different terms, provided the original work is properly cited, appropriate credit is given, any changes made indicated, and the use is non-commercial. See: http://creativecommons.org/licenses/by-nc/4.0/.

ORCID iDs

Liping Liu http://orcid.org/0000-0003-2943-055X

Yongjun Wang http://orcid.org/0000-0002-9976-2341

\section{REFERENCES}

1 van Asch CJ, Luitse MJ, Rinkel GJ, et al. Incidence, case fatality, and functional outcome of intracerebral haemorrhage over time, according to age, sex, and ethnic origin: a systematic review and meta-analysis. Lancet Neurol 2010;9:167-76.

2 Broderick JP, Brott TG, Duldner JE, et al. Volume of intracerebral hemorrhage. A powerful and easy-to-use predictor of 30-day mortality. Stroke 1993;24:987-93.

3 Liu J, Nie X, Gu H, et al. Tranexamic acid for acute intracerebral haemorrhage growth based on imaging assessment (TRAIGE): a multicentre, randomised, placebo-controlled trial. Stroke Vasc Neurol 2021;19:svn-2021-000942.

4 Nie X, Liu J, Liu D, et al. Haemostatic therapy in spontaneous intracerebral haemorrhage patients with high-risk of haematoma expansion by CT marker: a systematic review and meta-analysis of randomised trials. Stroke Vasc Neurol 2021;391:svn-2021-000941.

5 Awad IA, Polster SP, Carrión-Penagos J, et al. Surgical performance determines functional outcome benefit in the minimally invasive surgery plus recombinant tissue plasminogen activator for intracerebral hemorrhage evacuation (MISTIE) procedure. Neurosurgery 2019;84:1157-68.

6 Gregson BA, Mitchell P, Mendelow AD. Surgical decision making in brain hemorrhage, new analysis of the STICH, STICH II and STITCH(Trauma) Randomized Trials. Stroke 2019;50:1108-15.

7 Hanley DF, Lane K, McBee N, et al. Thrombolytic removal of intraventricular haemorrhage in treatment of severe stroke: results of the randomised, multicentre, multiregion, placebo-controlled clear III trial. Lancet 2017;389:603-11.

8 Wan J, Ren H, Wang J. Iron toxicity, lipid peroxidation and ferroptosis after intracerebral haemorrhage. Stroke Vasc Neurol 2019;4:93-5.

9 Selim M, Foster LD, Moy CS, et al. Deferoxamine mesylate in patients with intracerebral haemorrhage (i-DEF): a multicentre, randomised, placebo-controlled, double-blind phase 2 trial. Lancet Neurol 2019;18:428-38.

10 Rebchuk AD, O'Neill ZR, Szefer EK, et al. Health utility weighting of the modified Rankin scale: a systematic review and meta-analysis. JAMA Netw Open 2020;3:e203767.

11 Hanley DF, Thompson RE, Rosenblum M, et al. Efficacy and safety of minimally invasive surgery with thrombolysis in intracerebral haemorrhage evacuation (MISTIE III): a randomised, controlled, open-label, blinded endpoint phase 3 trial. Lancet 2019;393:1021-32.

12 Vespa P, Hanley D, Betz J, et al. ICES (intraoperative stereotactic computed Tomography-Guided endoscopic surgery) for brain hemorrhage. Stroke 2016;47:2749-55. 